\title{
Electrochemical Performance of Passive Film Formed on Ti-Al-Nb-Zr Alloy in Simulated Deep Sea Environments
}

\author{
Jing-Jing Dong ${ }^{1,2} \cdot$ Lin Fan $^{2} \cdot$ Hai-Bing Zhang ${ }^{2} \cdot$ Li-Kun Xu $^{2} \cdot$ Li-Li Xue $^{1}$
}

Received: 31 May 2019 / Revised: 15 July 2019 / Published online: 15 October 2019

(C) The Chinese Society for Metals (CSM) and Springer-Verlag GmbH Germany, part of Springer Nature 2019

\begin{abstract}
Titanium alloy $\mathrm{Ti}-\mathrm{Al}-\mathrm{Nb}-\mathrm{Zr}$ has high specific strength and becomes a promising structural material used in the deep sea. The excellent corrosion resistance of the alloy is derived from the protective passive film formed on its surface. By now, full agreement on interpretation of the anti-corrosion performance of the film in marine environment, especially in the deep sea, has not been reached. In this work, the electrochemical performance of two-surface-state $\mathrm{Ti}-\mathrm{Al}-\mathrm{Nb}-\mathrm{Zr}$ alloys which are treated by mechanical polishing and anodizing pre-passivation in the simulated shallow sea, $1000 \mathrm{~m}$ and $3000 \mathrm{~m}$ deep sea environments, is investigated. By interpreting the electrochemical kinetic parameters, it is found that the dominant cathodic process becomes hydrogen evolution in simulated deep sea environments, but the reduction rate is restrained by high hydrostatic pressure, which arrests the passivation of the alloy. Assisted by X-ray photoelectron spectroscopy analysis, it is found that the passive film mainly consists of titanium oxides. There are intermediate oxides with non-stoichiometric ratio involved in the film formation due to the low dissolved oxygen concentration and low temperature. The results of Mott-Schottky and electrochemical impedance show that the film has $n$-type semiconducting property with oxygen vacancies as the main point defects. The anti-corrosion performance in simulated deep sea environments is one order of magnitude lower than that in the simulated shallow sea environment. However, from 1000 to $3000 \mathrm{~m}$, the corrosion resistance is reduced very slightly. In the inner layers of the passive film and the passive film formed in simulated deep sea environments, the proportion of lowvalence titanium oxides is relatively high. The doping of low-valence titanium (Ti(II) or Ti(III)) results in a porous structure and ion permeability of the passive film, as well as relatively low corrosion resistance.
\end{abstract}

Keywords Titanium alloy $\cdot$ Oxide layer $\cdot$ Marine environment $\cdot$ Corrosion resistance $\cdot$ Mott-Schottky

\section{Introduction}

Titanium alloy is a kind of potential structural steel substitute material with high specific strength, corrosion resistance and heat resistance, which is being applied in more and more engineering fields. In particular, its corrosion resistance in marine environment is better than other metal materials. The

Available online at http://link.springer.com/journal/40195.

Lin Fan

fanl@ sunrui.net

1 College of Material Science and Chemical Engineering, Harbin Engineering University, 145 Nantong Road, Nangang District, Harbin 150001, China

2 State Key Laboratory for Marine Corrosion and Protection, Luoyang Ship Material Research Institute, Wenhai Road, Jimo District, Qingdao 266237, China excellent corrosion resistance of titanium alloy is derived from the protective passive film formed on its surface. The passive film of titanium alloy is usually very thin and in the form of adsorption film or three-dimensional phase-forming film, which makes it difficult to observe. The passive film reduces the active dissolution area of the metal surface or hinders the diffusion of reactive particles, which inhibits the corrosion of the metal substrate [1]. However, in the strongly reductive environment, anaerobic or anoxic environment, once the passive film of titanium alloy is ruptured, it will lead to the corrosion of the substrate due to the difficulty of its self-healing [2].

It has been shown that the passive film of titanium alloy is mainly composed of titanium oxides, as well as a small amount of oxide of alloying elements, such as $\mathrm{Mn}$ and $\mathrm{Cr}$, which will change the structure and property of the film [3]. The semiconducting properties of the passive film formed on titanium alloy in chloride medium at various $\mathrm{pH}$ conditions 
have been studied by Munirathinam et al. [4]. They found that the passivation film was $n$-type semiconducting film, and the diffusivity of point defects decreased with the increase of $\mathrm{pH}$. Compared with titanium alloy without passive film, the corrosion potential of titanium alloy with an anodic oxide film was more positive, and the electrochemical corrosion rate decreased significantly [5]. The anodic oxidation of titanium alloy in an anoxic aqueous solution has been thought to be controlled by the formation of intermediate oxide. To some extent, the electrochemical performance of the alloy is determined by the composition of passive film. Blackwood et al. [7] claimed that the uniform dissolution of passive film led to the enhancement of electrode activity. The electrochemical activity of passive film should be the inducement of localized corrosion [6]. The stability and dissolution rate of the passive film depended on the filmforming environment and the film-forming rate [8]. Alves et al. [9] pointed out that the rupture of the passive film of titanium alloy caused the temporary loss of corrosion resistance. When the passive film on the surface of titanium alloy was ruptured, there was a great difference in electrode potential formed between the passivation zone and the depassivation zone, causing galvanic corrosion $[10,11]$.

$\mathrm{Ti}-\mathrm{Al}-\mathrm{Nb}-\mathrm{Zr}$ alloy is designed to combine high mechanical strength with good adaptability to the marine environment and to serve as the main structural material in the deep sea at great depth. However, the anti-corrosion performance of the alloy as well as its passive film formed in marine environment, especially in the deep sea, is unclear. In this work, the electrochemical measurements and X-ray photoelectron spectroscopy (XPS) analysis were performed on two-surface-state $\mathrm{Ti}-\mathrm{Al}-\mathrm{Nb}-\mathrm{Zr}$ alloys which were treated by mechanical polishing and anodizing pre-passivation, respectively. The electrochemical performance of the alloy as well as its passive film preformed in the simulated shallow sea, $1000 \mathrm{~m}$ and $3000 \mathrm{~m}$ deep sea environments, was investigated. The influence of seawater depths on the electrochemical behavior of the alloy and the anti-corrosion property of the passive film was discussed.

\section{Experimental}

\subsection{Specimens and Solutions}

The specimens used in this work were made of a $\mathrm{Ti}-\mathrm{Al}-\mathrm{Nb}-\mathrm{Zr}$ (TANZ) titanium alloy, with the chemical composition (wt\%) of $6.033 \mathrm{Al}, 2.744 \mathrm{Nb}, 1.949 \mathrm{Zr}, 0.994$ Mo, $0.145 \mathrm{Si}, 0.185 \mathrm{Fe}, 0.05 \mathrm{C}, 0.05 \mathrm{~N}, 0.02 \mathrm{H}, 0.15 \mathrm{O}$ and Ti balance. For metallographic observation, the alloy was etched in Kroller reagent for 5-10 s after surface grinding and polishing. The TANZ alloy is a near- $\alpha$-titanium alloy, with the mixed microstructure of equiaxed grains ( $\alpha$-phase)

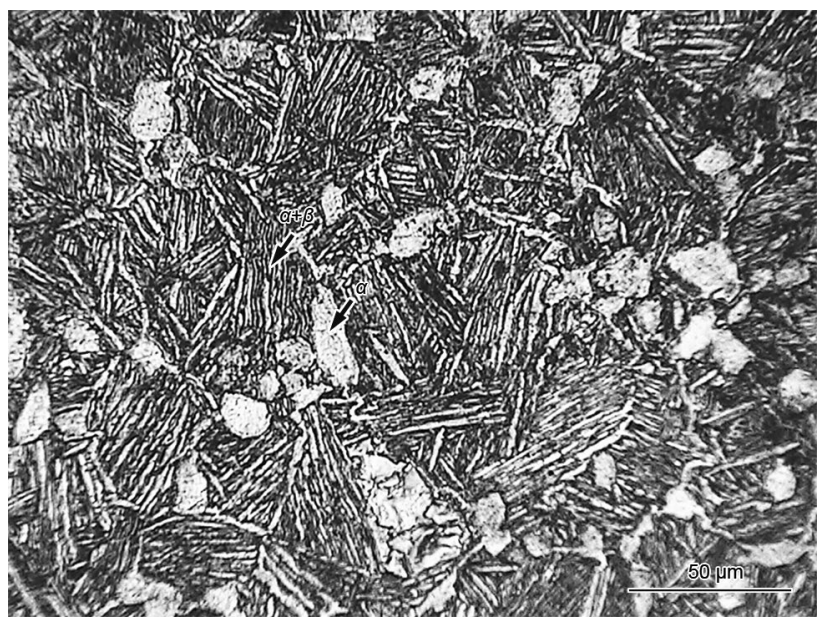

Fig. 1 Microstructure of TANZ alloy

Table 1 Simulated marine environments for electrochemical measurements

\begin{tabular}{lclll}
\hline Test condition & $\begin{array}{c}\text { Tempera- } \\
\text { ture }\left({ }^{\circ} \mathrm{C}\right)\end{array}$ & DO (ppm) & $\mathrm{pH}$ & Pressure (MPa) \\
\hline Shallow sea & 25 & 6.7 & 8.1 & 0.1 \\
1000 m deep sea & 4 & 2.6 & 7.7 & 10 \\
3000 m deep sea & 4 & 2.6 & 7.7 & 30 \\
\hline
\end{tabular}

and lamellar grains ( $\alpha+\beta$-phase) as shown in Fig. 1. Since the potential of $\alpha$-phase is more negative than the $\beta$-phase in lamellar grains, the oxide layer on $\alpha$-phase is more likely to be corroded and ruptured [12]. The specimens were embedded in epoxy resin with the working area of $1.0 \mathrm{~cm}^{2}$. Prior to the tests, all the specimens were ground from 100- to 1500-grit silicon carbide paper and transmitted immediately into the testing environments. Analytical reagent of sodium chloride and deionized water was used to prepare $3.5 \% \mathrm{NaCl}$ solution as the test solution. The simulated test environments were determined according to our previous actual marine environment experiments, and the parameters are listed in Table 1.

\subsection{Experimental Methods}

The test in the simulated shallow sea environment was conducted in an open system. A homemade device as shown in Fig. 2 was used to simulate the deep sea environments. The pressure in the vessel was controlled by adjusting the velocity of circulating solution, and the temperature was controlled by the cooling water circulator. The $\mathrm{pH}$ was adjusted by $\mathrm{NaOH}$, and the dissolved oxygen concentration (DO) was controlled by introducing proper amount of nitrogen gas into the solution. 


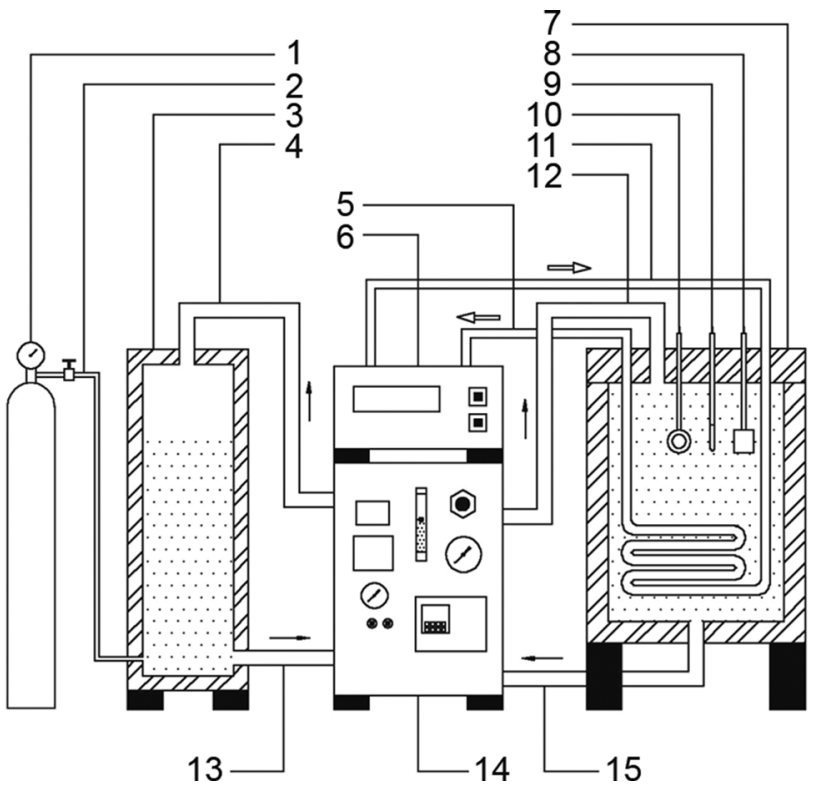

Fig. 2 Schematic diagram of deep sea environment simulation experiment device (1-high purity nitrogen, 2-gas inlet tube, 3-solution container, 4-solution container inlet pipe, 5-coolant outflow pipe, 6-cooling equipment, 7-high pressure vessel, 8-auxiliary electrode, 9-reference electrode, 10-working electrode, 11-coolant inflow pipe, 12-high pressure vessel inlet pipe, 13-solution container outlet pipe, 14-system control unit, 15-high pressure vessel outlet pipe)

Electrochemical experiments were performed with PARSTAT 4000, using a conventional three-electrode cell system, where TANZ alloy was used as the working electrode, and a platinum sheet as the auxiliary electrode. A saturated calomel electrode (SCE) was used as the reference electrode in the simulated shallow sea environment and an $\mathrm{Ag} / \mathrm{AgCl}$ solid-state electrode in simulated deep sea environments, respectively. All the potentials quoted in this work were converted to SCE. Two-surface-state specimens were prepared for electrochemical measurements. One of them was mechanically polished to remove the original oxide film on the surface, and the other was pre-passivated by anodic oxidation at a potential of $1000 \mathrm{mV}$ for $30 \mathrm{~min}$ in the simulated marine environments at various depths. Potentiodynamic polarization curves were acquired by scanning from -500 to $2000 \mathrm{mV}$ at a sweep rate of $0.167 \mathrm{mV} / \mathrm{s}$. Electrochemical impedance spectroscopy (EIS) tests were performed at open circuit potential with a frequency range of $100 \mathrm{kHz}-10 \mathrm{mHz}$ and AC sinusoidal wave amplitude of $10 \mathrm{mV}$. The test frequency of Mott-Schottky analysis was $100 \mathrm{~Hz}$, the scanning range was from -500 to $2000 \mathrm{mV}$, and the scanning rate was $50 \mathrm{mV} / \mathrm{s}$. XPS was used to compare the composition difference of passive film preformed in the simulated shallow sea and $3000 \mathrm{~m}$ deep sea environments. The composition distribution along the thickness direction of the passive film formed in simulated deep sea environments was also analyzed by intermittent XPS measurements. That is to say, the XPS measurements were performed after every $15 \mathrm{~min}$ argon ion sputtering with an etching rate of $0.5 \AA / \mathrm{min}$.

\section{Results}

\subsection{Potentiodynamic Polarization Curves}

Potentiodynamic polarization curves of TANZ alloy are shown in Fig. 3. There are obvious passive regions with high polarization resistance (high curve slope) just below a turning point at $1300 \mathrm{mV}$ for the two-surface-state alloys in all simulated marine environments. With reference to the literature [13], the pitting potential of titanium alloy in marine environment can reach several volts. Therefore, no film breakdown can be spotted in this polarization potential region. The turning point at $1300 \mathrm{mV}$ should be related
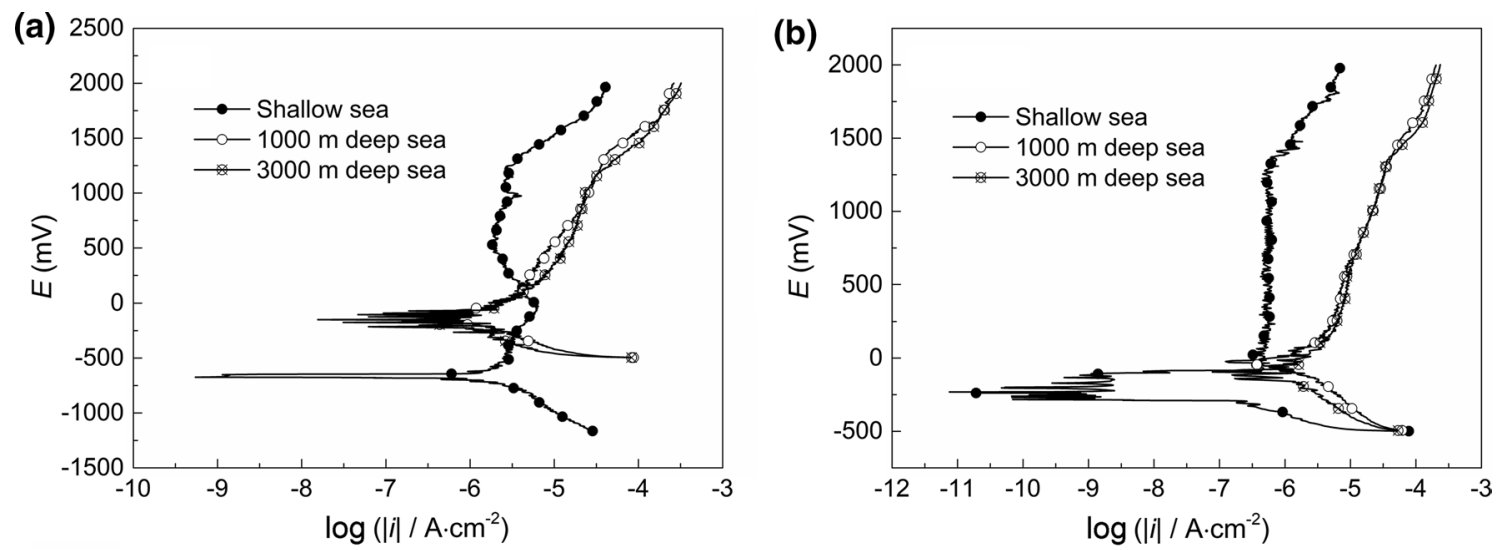

Fig. 3 Polarization curves of the mechanically polished (a), the pre-passivated (b) TANZ alloys in the simulated marine environments at various depths 
to the change of passive film composition. Therefore, it is reasonable to use the average current density in passivation region $\left(i_{\mathrm{p}}\right)$ to interpret the passivation behavior of the alloy. In the simulated shallow sea environment, $i_{\mathrm{p}}$ is $2.43 \mu \mathrm{A} /$ $\mathrm{cm}^{2}$ for the mechanically polished specimen, and a much smaller value of $0.56 \mu \mathrm{A} / \mathrm{cm}^{2}$ for the pre-passivated specimen is found due to the preformed surface layer. However, in simulated deep sea environments, the values of $i_{\mathrm{p}}$ are ca. one order of magnitude higher. Zhang et al. [14] pointed out that the corrosion resistance would decrease with the increase in hydrostatic pressure, which was distinguished by the increase of $i_{\mathrm{p}}$. Therefore, the increase of $i_{\mathrm{p}}$ in simulated deep sea environments indicates a reduced barrier property of the film.

In addition, the polarization parameters including corrosion potential $\left(E_{\text {corr }}\right)$, corrosion current density $\left(i_{\text {corr }}\right)$ and cathode Tafel slope $\left(b_{c}\right)$ are calculated and listed in Table 2. The anodic Tafel slope $\left(b_{\mathrm{a}}\right)$ is not given here, because it is not suitable for this passivation system to fit the anodic polarization curves using Tafel equation as declared by Duan et al. [15]. According to the findings of Zhang et al. [16], the most significant factor on $E_{\text {corr }}$ in simulated deep sea environments was temperature $(89.76 \%)$, followed by DO (10.24\%), and $E_{\text {corr }}$ shifted positively with the decrease in temperature or the increase of DO. As a result, $E_{\text {corr }}$ is found to be more positive in simulated deep sea environments because of relatively low temperature. There is little difference between $E_{\text {corr }}$ values of mechanically polished specimens at $1000 \mathrm{~m}$ and $3000 \mathrm{~m}$ depth due to the same test temperature and DO. For the pre-passivated specimens, $E_{\text {corr }}$ is more positive, while $i_{\text {corr }}$ is smaller in the simulated shallow sea environment, which indicates that it is beneficial to the formation of intact and stable passive film in sufficient oxygen-containing environment. The much higher $i_{\text {corr }}$ observed in simulated deep sea environments shows higher electrochemical activity of the preformed film. As pointed out by Cui et al. [8], the stability and dissolution rate of the passive film depended on the film-forming environment and the film-forming rate. It can be inferred that the simulated deep sea environments are not conducive to the formation and maintenance of passive film with high stability and low dissolution rate. It has been shown that low coverage uniformity [6] or high porosity [17] of the passive film induced by local dissolution can increase local electrochemical activity. As a result, the film shows low corrosion resistance. From 1000 to $3000 \mathrm{~m}$ seawater depth, the reduction in $E_{\text {corr }}$ should be related to the deteriorated anti-corrosion property of passive film. But the difference reflected in polarization parameters is quite small. It is also found that $b_{c}$ increases greatly from the simulated shallow sea to the deep sea environments, which is supposed to be induced by the change of cathodic process.

As shown in Fig. 4, in addition to the turning point at $1300 \mathrm{mV}$, another turning point at ca. $600 \mathrm{mV}$ appears for the pre-passivated specimens in simulated deep sea environments. Below $600 \mathrm{mV}$, the anodic dissolution is hindered by the preformed passive film, showing lower curve slope than that of the mechanically polished specimens. When the potential reaches $600 \mathrm{mV}$, the barrier effect fails, and the curve slopes corresponding to the two-surfacestate specimens tend to be consistent. Above $1300 \mathrm{mV}$, the dissolved $\mathrm{Ti}(\mathrm{II})$ will be further oxidized to Ti(III) or $\operatorname{Ti}(\mathrm{IV})[18,19]$, resulting in sharp increase in the current density.

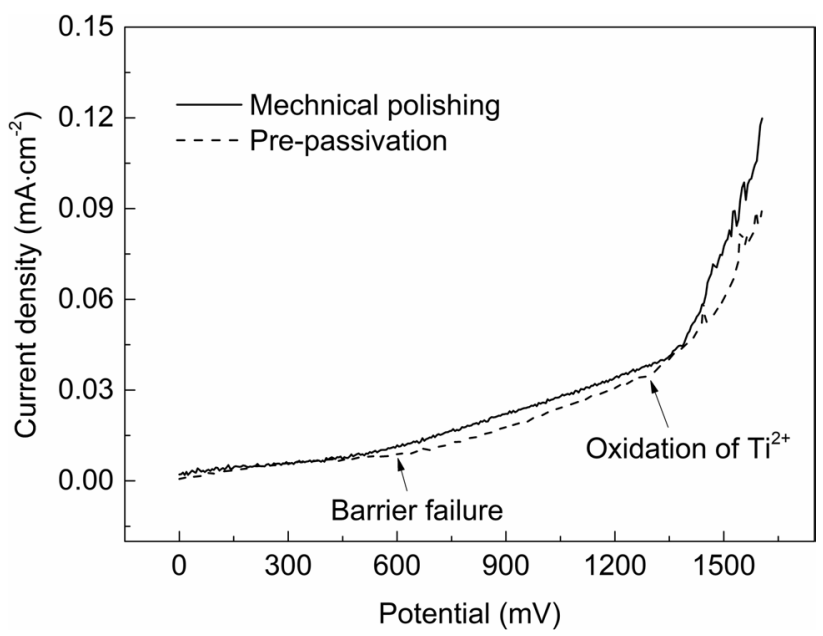

Fig. 4 Comparison of the anodic polarization curves of the two-surface-state TANZ alloys in the simulated $1000 \mathrm{~m}$ deep sea environment
Table 2 Calculated parameters of the polarization curves

\begin{tabular}{lllll}
\hline Surface state & Test condition & $E_{\text {corr }}(\mathrm{mV})$ & $i_{\text {corr }}\left(\mu \mathrm{A} \mathrm{cm}^{-2}\right)$ & $b_{\mathrm{c}}\left(\mathrm{mV} \mathrm{dec}^{-1}\right)$ \\
\hline Mechanical polishing & Shallow sea & -677 & 1.30 & 227 \\
& 1000 m deep sea & -160 & 1.05 & 270 \\
& 3000 m deep se & -166 & 0.68 & 293 \\
Pre-passivation & Shallow sea & -231 & 0.055 & 124 \\
& 1000 m deep sea & -41 & 1.11 & 299 \\
& 3000 m deep sea & -114 & 1.44 & 326 \\
\hline
\end{tabular}




\subsection{Electrochemical Impedance Spectroscopy}

For the pre-passivated TANZ alloy specimens, the amplitude of the capacitance arc in the Nyquist plot and the low frequency impedance in the Bode plot are considerably high in the simulated shallow sea environment, but decrease dramatically in simulated deep sea environments. Moreover, when the seawater depth varied from 1000 to $3000 \mathrm{~m}$, no pronounced impact on the electrochemical impedance behavior is found (Fig. 5). There are two time constants observed in Fig. 5b. They should correspond to the electrochemical responses of the solution/film interface and the film/metal substrate interface, respectively $[20,21]$.

Therefore, in addition to the electrode potential $E$, there is another time constant $\theta$ (oxide layer coverage on the alloy surface) which affects the reaction of the whole electrode [22]. Thus, the equivalent circuit as shown in Fig. 6 can be used to fit the curves. Where $R_{\mathrm{s}}$ is the solution resistance, $\mathrm{CPE}_{\mathrm{dl}}$ and $R_{\mathrm{t}}$ are the capacitance of double layer and the charge transfer resistance, respectively, and $\mathrm{CPE}_{\mathrm{f}}$ and $R_{\mathrm{f}}$ are the film capacitance and the film resistance, respectively. CPE represents the constant phase angle element, and $n$ is the dispersion coefficient. It can be seen from Table 3 that $R_{\mathrm{f}}$ and $R_{\mathrm{t}}$ decrease with the increase in seawater depth, while $\mathrm{CPE}_{\mathrm{f}}$ increases. It is generally believed that $R_{\mathrm{f}}$ and $\mathrm{CPE}_{\mathrm{f}}$ are related to the porosity and the water uptake of the film, respectively. It suggests that the film formed in simulated deep sea environments has a porous structure, which is conducive to water uptake and the diffusion of corrosive ions. In particular, $R_{\mathrm{t}}$ and $R_{\mathrm{f}}$ decrease by an order of magnitude compared with those in the simulated shallow sea environment, indicating that the charge transfer resistance at the interface is significantly reduced. Therefore, the barrier effect of the preformed passive film is obviously weakened in these environments. Due to the increase in film porosity and the deterioration

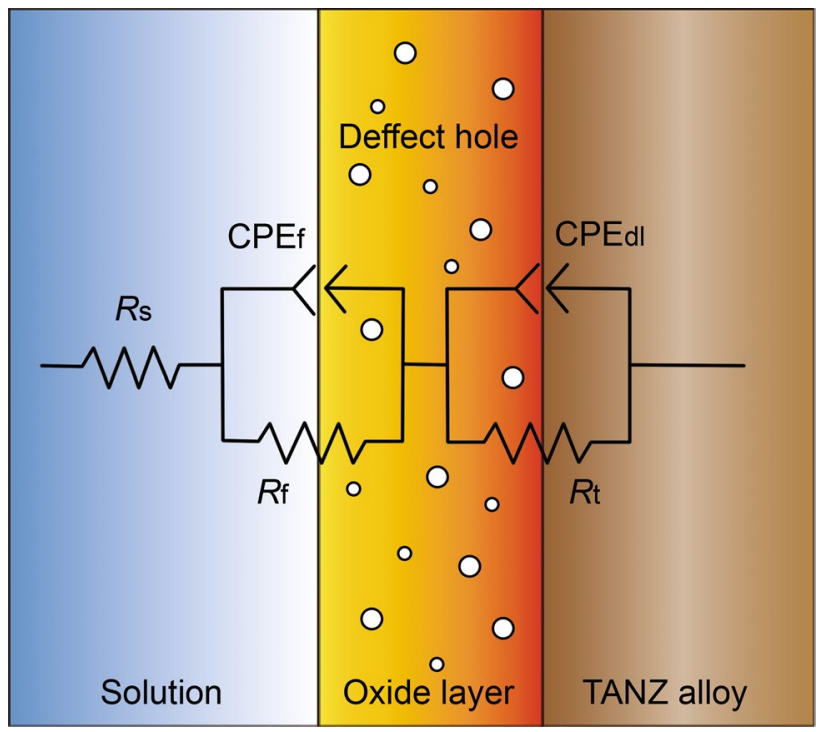

Fig. 6 Schematic diagrams of equivalent circuits for the pre-passivated TANZ alloy

of barrier property of the film, the dispersion effect at the solution/film interface is attenuated, demonstrated in the increase of $n_{\mathrm{f}}$ with the increase in seawater depth.

\subsection{Mott-Schottky Analysis}

In order to analyze the semiconducting property of the film formed by anodic oxidation in the simulated marine environments, Mott-Schottky curves were measured. It can be seen from Fig. 7 that the curve slope of depletion layer (the potential range is ca. $500-1000 \mathrm{mV}$ ) is positive, indicating that the passive film has $n$-type semiconducting property. Therefore, the relationship between the differential capacitance of the space charge layer $\left(C_{\mathrm{SC}}\right)$ and the bulk potential $E$ of the semiconducting film can be expressed by formula (1) $[23,24]$.
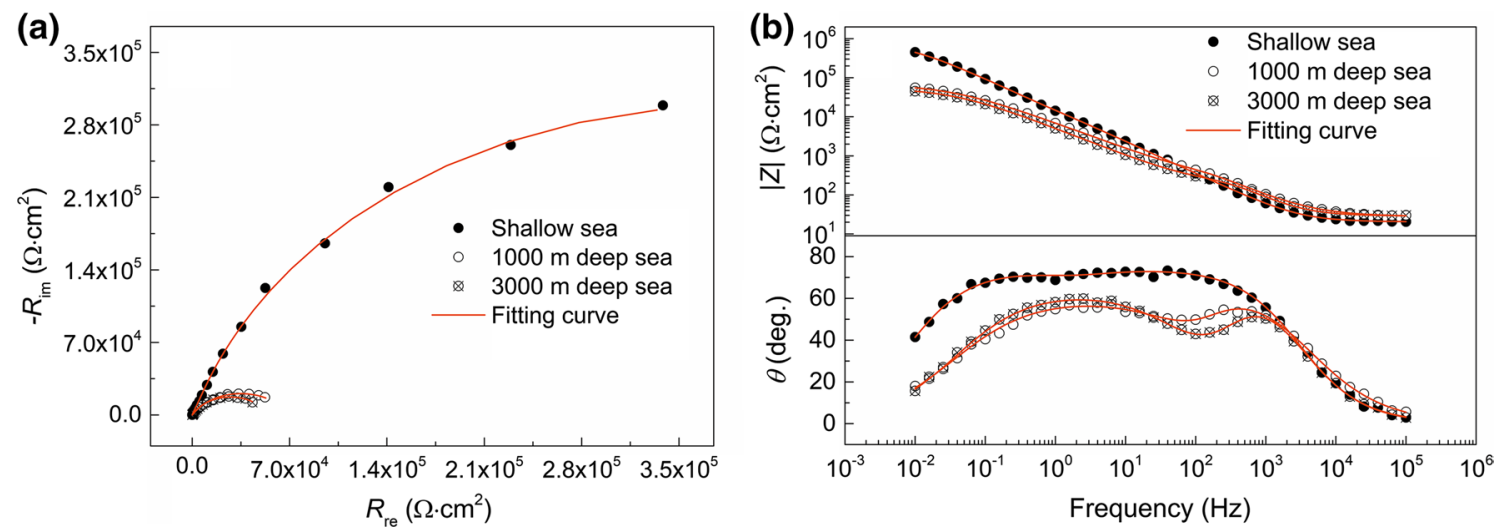

Fig. 5 Nyquist plots (a), bode plots (b) of the pre-passivated TANZ alloy in the simulated marine environments at various depths 
Table 3 Calculated parameters of the EIS plots

\begin{tabular}{lllllllc}
\hline Test condition & $R_{\mathrm{s}}\left(\Omega \mathrm{cm}^{2}\right)$ & $\begin{array}{l}\mathrm{CPE}_{\mathrm{f}} \\
\left(\mu \mathrm{S} \mathrm{s}^{n} \mathrm{~cm}^{-2}\right)\end{array}$ & $n_{\mathrm{f}}$ & $R_{\mathrm{f}}\left(\mathrm{k} \Omega \mathrm{cm}^{2}\right)$ & $\begin{array}{l}\mathrm{CPE}_{\mathrm{dl}} \\
\left(\mu \mathrm{S} \mathrm{s}^{n} \mathrm{~cm}^{-2}\right)\end{array}$ & $n_{\mathrm{dl}}$ & $R_{\mathrm{t}}\left(\mathrm{k} \Omega \mathrm{cm}^{2}\right)$ \\
\hline Shallow sea & 20.45 & 27.21 & 0.82 & 12.70 & 15.42 & 0.83 & 780.10 \\
1000 m deep sea & 27.69 & 58.65 & 0.96 & 1.54 & 40.12 & 0.80 & 68.14 \\
3000 m deep sea & 28.55 & 60.65 & 0.97 & 1.33 & 51.63 & 0.82 & 53.26 \\
\hline
\end{tabular}

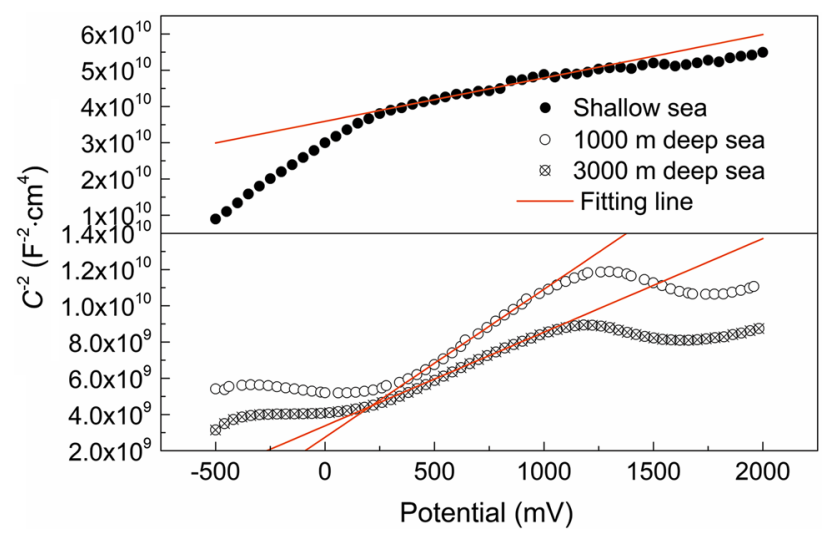

Fig. 7 Mott-Schottky curves of the pre-passivated TANZ alloy in the simulated marine environments at various depths

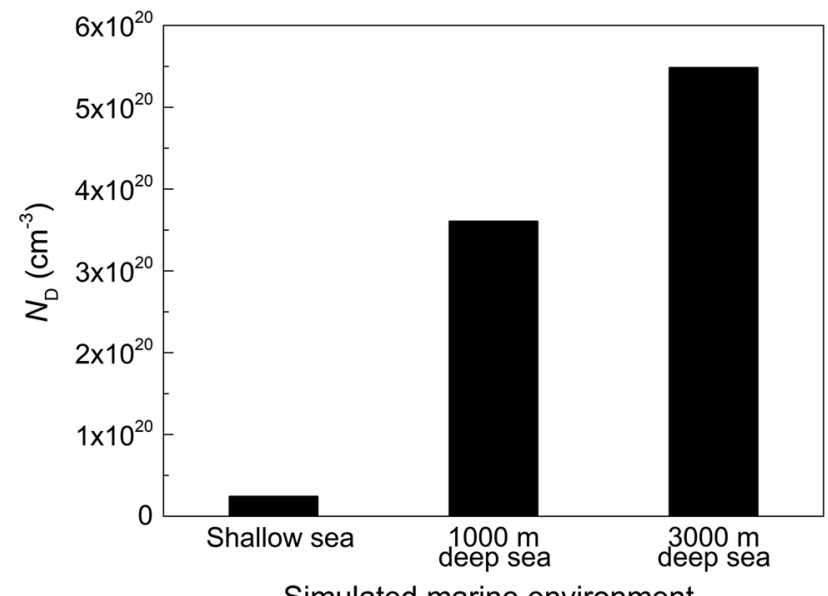

Fig. 8 Donor density of the pre-passivated TANZ alloy in the simulated marine environments at various depths

$C_{\mathrm{SC}}^{-2}=\frac{2}{e \varepsilon_{\mathrm{r}} \varepsilon_{0} N_{\mathrm{D}}}\left(\left|E-E_{\mathrm{fb}}\right|-\frac{\kappa T}{e}\right)$

where $e$ is the electron quantity $\left(1.602189 \times 10^{-19} \mathrm{C}\right)$, $\varepsilon_{\mathrm{r}}$ is the relative dielectric constant of Ti oxide layer (48 was applied in this work), $\varepsilon_{0}$ is the vacuum permittivity $\left(8.85 \times 10^{-14} \mathrm{~F} / \mathrm{cm}\right), N_{\mathrm{D}}$ is the donor density, $E_{\mathrm{fb}}$ is the flat-band potential, $\kappa$ is the Boltzmann constant $\left(1.38 \times 10^{-23} \mathrm{~J} / \mathrm{K}\right)$, and $T$ is the absolute temperature.
$N_{\text {D }}$ was obtained by fitting the straight line of depletion layer in Fig. 7 with formula (1) and is shown in Fig. 8. $N_{\mathrm{D}}$ increases with the increase in seawater depth. In particular, the donor density increases by an order of magnitude from the simulated shallow sea to the deep sea environments. It means that the higher the seawater depth is, the more defects the film has. Cui et al. [25] indicated that the defects had high energy and high activity, which facilitated the anodic dissolution. Consequently, the stability and corrosion resistance of the preformed passive film decrease. However, from 1000 to $3000 \mathrm{~m}$ seawater depth, the corrosion resistance is reduced very slightly, which is consistent with the results of polarization and EIS measurements.

\section{Discussion}

\subsection{Effect of Seawater Depth on the Electrochemical Behavior of TANZ Alloy}

The possible cathodic reactions in marine environments are oxygen reduction and hydrogen evolution [26, 27]:

$\mathrm{O}_{2}+2 \mathrm{H}_{2} \mathrm{O}+4 \mathrm{e}^{-} \rightarrow 4 \mathrm{OH}^{-}$

$2 \mathrm{H}_{2} \mathrm{O}+2 \mathrm{e}^{-} \rightarrow \mathrm{H}_{2}+2 \mathrm{OH}^{-}$

Their electrode potentials should be expressed by:

$E_{\mathrm{O}_{2} / \mathrm{OH}^{-}}=E_{\mathrm{O}_{2} / \mathrm{OH}^{-}}^{\Theta}+\frac{2.303 R T}{n F} \log \frac{\frac{p_{\mathrm{O}_{2}}}{p^{\Theta}}}{\left[\mathrm{OH}^{-}\right]^{4}}$

$E_{\mathrm{H}_{2} \mathrm{O} / \mathrm{H}_{2}}=E_{\mathrm{H}_{2} \mathrm{O} / \mathrm{H}_{2}}^{\Theta}+\frac{2.303 R T}{n F} \log \frac{1}{\frac{p_{\mathrm{H}_{2}}}{p^{\theta}}\left[\mathrm{OH}^{-}\right]^{2}}$

where $R$ is the ideal gas constant, $n$ is the electron number of electrode reaction, $F$ is the Faraday constant, $p_{\mathrm{O}_{2}} / p^{\Theta}$ and $p_{\mathrm{H}_{2}} / p^{\Theta}$ are the partial pressure of $\mathrm{O}_{2}$ and $\mathrm{H}_{2} \cdot E_{\mathrm{O}_{2} / \mathrm{OH}^{-}}^{\Theta}$, and $E_{\mathrm{H}_{2} \mathrm{O} / \mathrm{H}_{2}}^{\Theta}$ are the standard electrode potentials of oxygen reduction and hydrogen evolution. Thus, in the simulated shallow sea environment, the electrode potentials for reaction (2) and (3) are 639 and $-590 \mathrm{mV}$, respectively. Under this condition, the cathodic process shows more oxygen depolarization tendency. However, the oxygen reduction is 
suppressed in simulated deep sea environments with low DO and low temperature. The values of $p_{\mathrm{O}_{2}} / p^{\Theta}$ and $p_{\mathrm{H}_{2}} / p^{\Theta}$ in formulas (4) and (5) tend to be zero at high hydrostatic pres-

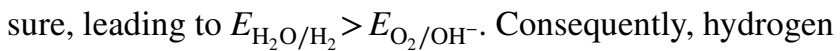
evolution is more likely to occur $[28,29]$.

The formula $b_{\mathrm{c}}=2.303 \mathrm{RT} / \beta n_{\mathrm{c}} F$ was used to calculate the cathodic Tafel slope as shown in Fig. 3b. If the transfer coefficient $\beta$ of cathodic reaction is 0.5 and the charge number $n_{\mathrm{c}}$ is 1 [30], the theoretical value of $b_{\mathrm{c}, 0}$ should be $110 \mathrm{mV} / \mathrm{dec}$ in simulated deep sea environments. But the calculated result of $b_{\mathrm{c}}$ is higher than $b_{\mathrm{c}, 0}$ and increases slightly with the increase in seawater depth. Therefore, it is speculated that the hydrogen evolution reaction in simulated deep sea environments may undergo the following procedures. Firstly, the hydrated hydrogen ions discharge to become the adsorbed hydrogen molecular ions; secondly, the adsorbed hydrogen molecular ions are further reduced to form hydrogen molecules and released from the surface of the electrode.

$\mathrm{H}_{3}^{+} \mathrm{O}+m e^{-} \rightarrow \frac{1}{2} \mathrm{H}_{2}^{(2-2 m)+}+\mathrm{H}_{2} \mathrm{O}$

$\mathrm{H}_{2}^{(2-2 m)+}+(2-2 m) e^{-} \rightarrow \mathrm{H}_{2}$

where $m=b_{\mathrm{c}, 0} / b_{\mathrm{c}}, 0<m<1$.

If reaction (6) is a controlling step, the average number of electrons captured by each hydrated hydrogen ion in the reaction is $m$, which is less than 1 [31,32]. The phenomenon may be due to the difficulty of desorption of generated hydrogen under high hydrostatic pressure in simulated deep sea environments. The forward reaction of reaction (3) is restrained, while the reverse reaction is favored. As a result, the discharge of hydrogen ion at the electrode surface is reduced, and the electrochemical activity or the reaction rate of the whole electrode process is attenuated, resulting in the decrease in passivation ability of the alloy [33].

It has been found that titanium can bond with oxygen in numerous ways resulting in varying stoichiometry depending on the reaction conditions [34]. Hong et al. [35] indicated that the anodic oxidation of titanium alloy in an anoxic aqueous solution was controlled by the formation of intermediate oxide. Therefore, during the transformation of the film oxides from divalent titanium oxides to trivalent and tetravalent titanium oxides, the intermediate oxides with non-stoichiometric ratio may exist, i.e., $\mathrm{TiO}_{1+x}, 0<x<1$. This is because that the diffusion velocity and the discharge process of dissolved oxygen are limited in simulated deep sea environments with relatively low DO and low temperature. The intermediate oxides have been thought to be unstable and porous, as well as have loose texture, while $\mathrm{TiO}_{2}$ film is more intact and protective [36]. Therefore, it can be deduced that the passive film formed in the simulated shallow sea environment contains more fully grown $\mathrm{TiO}_{2}$ oxides which act as an effective barrier for the mass transfer.

\subsection{Effect of Seawater Depth on the Anti-corrosion Property of Passive Film of TANZ Alloy}

For the pre-passivated TANZ alloys, considering the dispersing effect, the impedance of $\mathrm{CPE}_{\mathrm{f}}$ should be expressed as [37]:

$Z_{\mathrm{CPE}}=\frac{1}{Y_{0}(j \omega)^{n}}$

where $Y_{0}$ represents the CPE constant.

If the solution resistance is ignored, the time constant in the high-frequency region of EIS plot becomes $R_{0} Y_{0}$. When the high-frequency phase angle is $-45^{\circ}$, the corresponding frequency is usually chosen as the characteristic frequency $[38,39]$. At this frequency,

$$
\begin{array}{r}
Z_{\mathrm{re}}=\frac{\frac{1}{R_{0}}+Y_{0} \omega^{n} \cos \left(\frac{n \pi}{2}\right)}{\left(\frac{1}{R_{0}}\right)^{2}+\left(\frac{2}{R_{0}}\right) Y_{0} \omega^{n} \cos \left(\frac{n \pi}{2}\right)+\left(Y_{0} \omega^{n}\right)^{2}}=-Z_{\mathrm{im}} \\
=\frac{Y_{0} \omega^{n} \sin \left(\frac{n \pi}{2}\right)}{\left(\frac{1}{R_{0}}\right)^{2}+\left(\frac{2}{R_{0}}\right) Y_{0} \omega^{n} \cos \left(\frac{n \pi}{2}\right)+\left(Y_{0} \omega^{n}\right)^{2}}
\end{array}
$$

By simplification, the following formula is obtained:

$\frac{1}{R_{0} Y_{0}}=\omega^{n}\left[\sin \left(\frac{n \pi}{2}\right)-\cos \left(\frac{n \pi}{2}\right)\right]$

The relationship between $R_{0}$ and the porosity of the film $P$ is that $R_{0}=R_{0}^{0} /(P S)$ [40], where $R_{0}^{0}$ is the film resistance per unit area, and $S$ is the surface area of the film. In this work, $S=1$; therefore,

$\omega^{\prime}=2 \pi f^{\prime}=\frac{P}{R_{0}^{0} Y_{0}}=\omega^{n}\left[\sin \left(\frac{n \pi}{2}\right)-\cos \left(\frac{n \pi}{2}\right)\right]$

where $\omega^{\prime}$ or $f^{\prime}$ was obtained by the correction of the measured frequency $\omega$ or $f$ with $n$ value $\left(n=n_{\mathrm{f}}\right)$. Assuming that $R_{0}^{0}$ and $Y_{0}$ are invariant, the modified characteristic frequency will be proportional to the porosity of the film.

The measured values of $f$ are $2018 \mathrm{~Hz}$ in the simulated shallow sea environment, $1953 \mathrm{~Hz}$ and $1782 \mathrm{~Hz}$ in the simulated $1000 \mathrm{~m}$ and $3000 \mathrm{~m}$ deep sea environments, respectively. By using formula (11), the values of $f^{\prime}$ after correction become $251 \mathrm{~Hz}$ in the simulated shallow sea environment, $1253 \mathrm{~Hz}$ and $1282 \mathrm{~Hz}$ in the simulated $1000 \mathrm{~m}$ and $3000 \mathrm{~m}$ deep sea environments, respectively. Therefore, the porosity of the film increases with the increase in seawater depth, 
indicating that the anti-corrosion property of the film is reduced.

XPS results show that $\mathrm{TiO}_{2}$ oxide accounts for the majority in the outer layer of passive film. In addition, the spectra are not spikes, but overlapped peaks near the binding energy of the major species, i.e., $\mathrm{TiO}, \mathrm{Ti}_{2} \mathrm{O}_{3}$ and $\mathrm{TiO}_{2}$. This is more evident for the layer formed in simulated deep sea environments. This result further confirms the existence of intermediate oxides with non-stoichiometric ratio [41]. For convenience, only titanium oxides with stoichiometric ratio, i.e., $\mathrm{TiO}, \mathrm{Ti}_{2} \mathrm{O}_{3}$ and $\mathrm{TiO}_{2}$, were involved in calculating the composition of passive film. It can be seen from Fig. 9 that the content of $\mathrm{TiO}_{2}$ is low, while the contents of $\mathrm{TiO}$ and $\mathrm{Ti}_{2} \mathrm{O}_{3}$ are high in simulated deep sea environments. From the outer layer to the inner layer, the content of $\mathrm{TiO}_{2}$ decreases, while $\mathrm{TiO}$ and $\mathrm{Ti}_{2} \mathrm{O}_{3}$ increase rapidly (Fig. 10).

According to the point defect model (PDM), the defects in the $n$-type oxide layer can be in the form of oxygen vacancies [42] which are caused by the doping of low-valence titanium ( $\mathrm{Ti}(\mathrm{II})$ or $\mathrm{Ti}(\mathrm{III})$ ) in $\mathrm{TiO}_{2}$ oxide layer. With the increase in the proportion of doped $\mathrm{Ti}(\mathrm{II})$ or $\mathrm{Ti}(\mathrm{III})$, the amount of oxygen vacancies increases. Therefore, it can be acknowledged that the anti-corrosion performance decreases from the outer layer

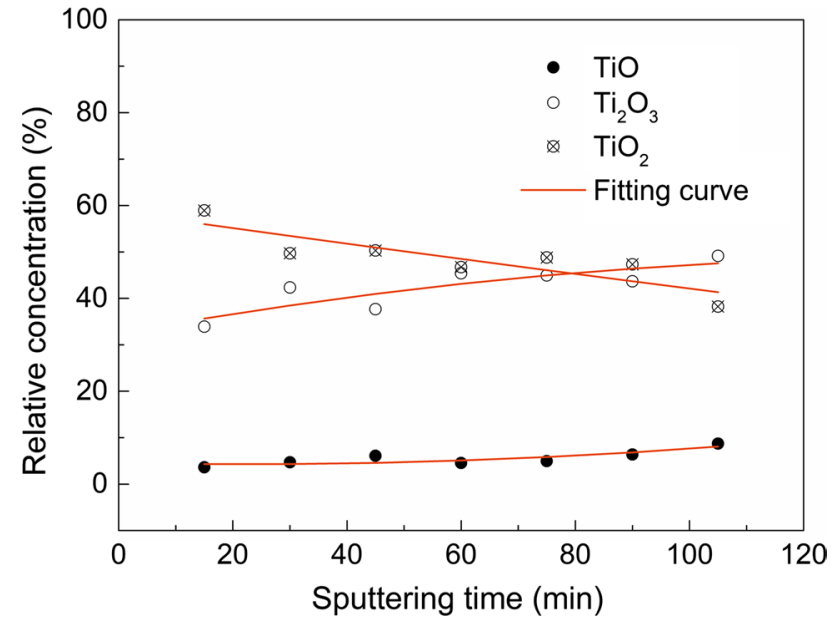

Fig. 10 Distribution of titanium oxides formed in the simulated $3000 \mathrm{~m}$ deep sea environment

to the inner layer with the increase in low-valence titanium oxides, i.e., $\mathrm{TiO}$ and $\mathrm{Ti}_{2} \mathrm{O}_{3}$. Noting that the film formed in simulated deep sea environments exhibits higher donor densities, revealing a porous and highly conductive passive film.
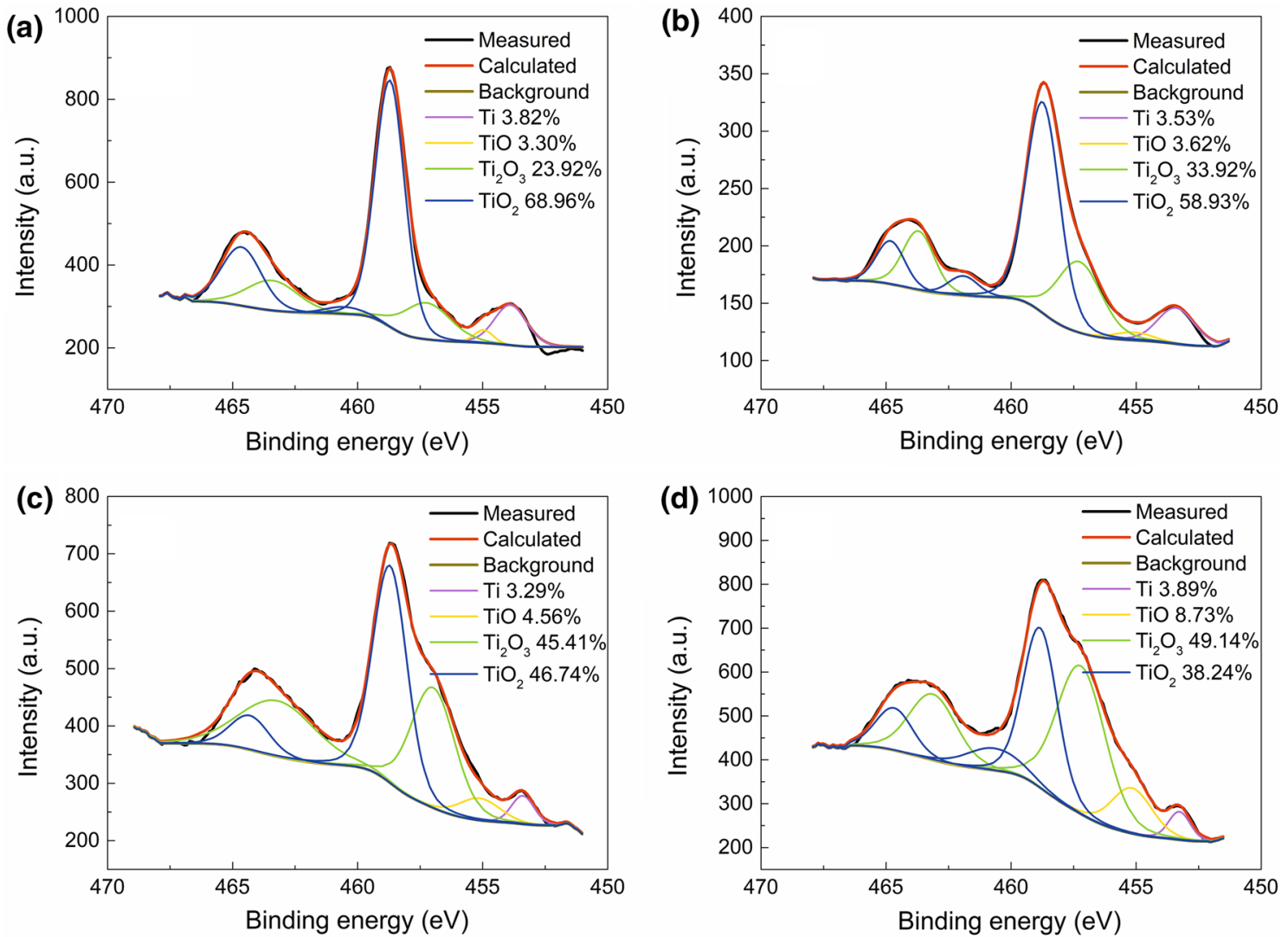

Fig. 9 XPS results of passive film formed in the simulated shallow sea environment (a) and $3000 \mathrm{~m}$ deep sea environment after the etching time of $15 \min (\mathbf{b}), 60 \min (\mathbf{c}), 105 \min (\mathbf{d})$ 
The reason may be that the adsorbed hydrogen is difficult to annihilate due to the high hydrogen partial pressure. Amri et al. [43] indicated that hydrogen would adsorb at the film/ electrolyte interface and generate anionic oxygen vacancies increasingly by reacting with oxygen. Therefore, hydrogen is easily captured by the lattice oxygen, creating more oxygen vacancies which increase the charge carrier density in the film. This is also consistent with the PDM model as shown by Cui et al. [44]. These point defects may facilitate the formation of a porous and ion permeable film, promote the diffusion of corrosive media and increase the local electrochemical activity [45]. Therefore, in simulated deep sea environments with low DO and high hydrostatic pressure, the corrosion resistance of the oxide layer is greatly reduced.

\section{Conclusions}

1. The hydrogen evolution is the dominant cathodic process in simulated deep sea environments, but the reduction reaction is restrained under the effect of high hydrostatic pressure. The average number of electrons captured by each hydrogen atom in the hydrogen reduction reaction is less than 1, the passivation ability of TANZ alloy is reduced correspondingly, leading to the great increase in cathode Tafel slope.

2. The passive film formed by anodic oxidation mainly consists of titanium oxide and shows $n$-type semiconducting property. There are intermediate oxides with non-stoichiometric ratio involved in the film formation due to low dissolved oxygen concentration (DO) in simulated deep sea environments.

3. The corrosion resistance of passive film formed in simulated deep sea environments is about one order of magnitude lower than that formed in the simulated shallow sea environment, reflected in the extremely low electrochemical impedance and high film defects (oxygen vacancies).

4. The inner layer of the passive film and the film formed in simulated deep sea environments are doped with more low-valence titanium (Ti(II) or Ti(III)), leading to a porous structure and ion permeability of the passive film, as well as relatively low corrosion resistance.

Acknowledgements This work was financially supported by the National Key Basic Research Program of China (Grant No. 2017-JCJQ-ZD-024).

\section{References}

[1] A.K. Shukla, R. Balasubramaniam, S. Bhargava, Intermetallics 13, 631 (2005)
[2] S. Barison, S. Cattarin, S. Daolio, M. Musiani, A. Tuissi, Electrochim. Acta 50, 11 (2004)

[3] K. Zhu, N. Gui, T. Jiang, M. Zhu, X. Lu, J.Y. Zhang, C.H. Li, Metall. Mater. Trans. A 45, 1761 (2014)

[4] B. Munirathinam, R. Narayanan, L. Neelakantan, Thin Solid Films 598, 260 (2016)

[5] J. Dai, J. Zhu, C. Chen, F. Weng, J. Alloys Compd. 685, 784 (2016)

[6] T. Li, J.R. Scully, G.S. Frankel, J. Electrochem. Soc. 165, C762 (2018)

[7] J. Pang, D.J. Blackwood, Corros. Sci. 105, 17 (2016)

[8] Z. Cui, L. Wang, M. Zhong, F. Ge, H. Gao, C. Man, C. Liu, X. Wang, J. Electrochem. Soc. 165, C542 (2018)

[9] A.C. Alves, F. Wenger, P. Ponthiaux, J.-P. Celis, A.M. Pinto, L.A. Rocha, J.C.S. Fernandes, Electrochim. Acta 234, 16 (2017)

[10] S.A. Policastro, R.M. Anderson, D.F. Roeper, D.J. Horton, Electrochim. Acta 224, 419 (2017)

[11] N. Khayatan, H.M. Ghasemi, M. Abedini, Wear 380-381, 154 (2017)

[12] D. Wei, X. Chen, P. Zhang, F. Ding, F. Li, Z. Yao, Appl. Surf. Sci. 441, 448 (2018)

[13] N. Dai, L. Zhang, J. Zhang, Q. Chen, M. Wu, Corros. Sci. 102, 484 (2016)

[14] T. Zhang, Y. Yang, Y. Shao, G. Meng, F. Wang, Electrochim. Acta 54, 3915 (2009)

[15] G. Duan, L. Yang, S. Liao, C. Zhang, X. Lu, Y. Yang, B. Zhang, Y. Wei, T. Zhang, B. Yu, X. Zhang, F. Wang, Corros. Sci. 135, 197 (2018)

[16] Q. Hu, Y. Liu, T. Zhang, S. Geng, F. Wang, J. Mater. Sci. Technol. 35, 168 (2019)

[17] T.M. Serikov, NKh Ibrayev, N. Nuraje, S.V. Savilov, V.V. Lunin, Russ. Chem. Bull. 66, 614 (2017)

[18] Y. Huang, D.J. Blackwood, Electrochim. Acta 51, 1099 (2005)

[19] S.L. de Assis, S. Wolynec, I. Costa, Electrochim. Acta 51, 1815 (2006)

[20] A.U. Chaudhry, B. Mansoor, T. Mungole, G. Ayuob, D.P. Field, Electrochim. Acta 264, 69 (2018)

[21] S.M. Bhola, R. Bhola, B. Mishra, D.L. Olson, J. Mater. Sci. 45, 6179 (2010)

[22] J.N. Laboulais, A.A. Mata, V.A. Borrás, A.I. Muñoz, Electrochim. Acta 227, 410 (2017)

[23] M.C.K. Sellers, E.G. Seebauer, Thin Solid Films 519, 2103 (2011)

[24] Z. Cui, L. Wang, H. Ni, W. Hao, C. Man, S. Chen, X. Wang, Z. Liu, X. Li, Corros. Sci. 118, 31 (2017)

[25] Z. Cui, S. Chen, L. Wang, C. Man, Z. Liu, J. Wu, X. Wang, S. Chen, X. Li, J. Electrochem. Soc. 164, C856 (2017)

[26] N. Comisso, L. Armelao, S. Cattarin, P. Guerriero, L. Mattarozzi, M. Musiani, M. Rancan, L. Vázquez-Gómez, E. Verlato, Electrochim. Acta 273, 454 (2018)

[27] H. Tian, X. Wang, Z. Cui, Q. Lu, L. Wang, L. Lei, Y. Li, D. Zhang, Corros. Sci. 144, 145 (2018)

[28] F. Sun, S. Ren, Z. Li, Z. Liu, X. Li, C. Du, Mater. Sci. Eng. A 685 , 145 (2017)

[29] Y. Yang, T. Zhang, Y. Shao, G. Meng, F. Wang, Corros. Sci. 52, 2697 (2010)

[30] T. Zhao, Z. Liu, C. Du, M. Sun, X. Li, Int. J. Fatigue 110, 105 (2018)

[31] Y. Doi, M. Tamaki, Inorg. Chim. Acta 64, L145 (1982)

[32] Z. Yang, B. Kan, J. Li, Y. Su, L. Qiao, J. Electroanal. Chem. 822, $123(2018)$

[33] A. Chojnacka, J. Kawalko, H. Koscielny, J. Guspiel, A. Drewienkiewicz, M. Bieda, W. Pachla, M. Kulczyk, K. Sztwiertnia, E. Beltowska-Lehman, Appl. Surf. Sci. 426, 987 (2017)

[34] R. Roy, W.B. White, J. Crystal Growth 13-14, 78 (1972)

[35] S.H. Hong, Acta Chem. Scand. 36, 207 (1982) 
[36] W. Liu, X. Cao, S. Peng, X. Long, S. Luo, W. Wang, Surf. Technol. 36, 51 (2007)

[37] H. Luo, H. Su, C. Dong, X. Li, Appl. Surf. Sci. 400, 38 (2017)

[38] A. Fattah-Alhosseini, M. Naseri, S.O. Gashti, S. Vafaeian, M.K. Keshavarz, Corros. Sci. 131, 81 (2018)

[39] K. Liu, J.G. Duh, J. Mater. Sci. 43, 3589 (2008)

[40] Y. Zuo, R. Pang, W. Li, J. Xiong, Y. Tang, Corros. Sci. 50, 3322 (2008)

[41] N.A. Sapoletova, S.E. Kushnir, K.S. Napolskii, Electrochem. Commun. 91, 5 (2018)
[42] C. da Fonseca, S. Boudin, Belo M. da Cunha, J. Electroanal. Chem. 379, 173 (1994)

[43] J. Amri, T. Souier, B. Malki, B. Baroux, Corros. Sci. 50, 431 (2008)

[44] Z. Cui, S. Chen, Y. Dou, S. Han, L. Wang, C. Man, X. Wang, S. Chen, Y.F. Cheng, X. Li, Corros. Sci. 150, 218 (2019)

[45] J.G. Odhiambo, L. Zhang, T. Liu, L. Dong, Y. Yin, Appl. Mech. Mater. 513-517, 189 (2014) 